\title{
A HARMONIA ENTRE RAZÃo E ORAÇÃo NO PENSAMENTO DE Anselmo de Aosta
}

\author{
Manoel Vasconcellos ${ }^{1}$
}

\begin{abstract}
Resumo: O presente artigo busca analisar uma das oraçôes elaboradas por Anselmo de Aosta (10331109), mais precisamente, a Oração a São Nicolau, procurando mostrar como é possível encontrar, refletidos na prece, aspectos relevantes da produção filosófico-teológica do autor, sobretudo, em relação à situaçáo do homem, marcado pelo pecado, uma vez que abandonou a retidáo da vontade. Na prece, bem como em sua obra especulativa, Anselmo examina a situaçáo do homem pecador, diante da graça e misericórdia divinas. Almejamos ressaltar a existência, na obra anselmiana, de uma harmoniosa relação entre oraçáo e trabalho especulativo, em conformidade com o ideal beneditino do ora et labora.
\end{abstract}

Palavras-Chave: Anselmo. Oração. Homem. Pecado.

Anselmo de Aosta (1033-1109), além da sua produção filosóficoteológica, propriamente dita, escreveu também três grandes meditações (para despertar o temor, sobre a perda da virgindade e sobre a redenção humana), centenas de cartas e dezenove oraçóes. Tais preces abarcam variados temas e têm diversos destinatários, posto que são dirigidas a Deus, a Cristo, a diversos personagens bíblicos, tais como, três oraçôes dirigidas à Virgem Maria, além das orações a João Batista, João Evangelista, Pedro, Paulo, Estevão e Maria Madalena. Há oraçóes com abordagens específicas: para receber a Eucaristia, oração à Santa Cruz, oração para amar a Deus e ao próximo, há uma oração pelos amigos e outra pelos inimigos. Além disso, há uma oração em que um bispo ou abade dirige-se ao santo em cujo nome ele governa a Igreja.

Há ainda duas oraçôes que são dirigidas a santos que não são personagens bíblicos: uma delas é a oração a São Bento, o fundador da ordem

${ }_{1}^{1}$ Professor da Universidade Federal de Pelotas (UFPel) e do Programa de Pós-Graduação em Filosofia da UFPel, Pelotas, RS - Brasil. (D) https://orcid.org/0000-0001-7896-5417 Email: vasconcellos. manoel@gmail.com

http://dx.doi.org/10.1590/0101-3173.2019.v42esp.12.p217

This is an open-access article distributed under the terms of the Creative Commons Attribution License. 
beneditina, instituição a que Anselmo está vinculado, desde sua chegada, ainda muito jovem, à abadia de Bec, na Normandia, onde permaneceu por trinta e três anos; a outra carta é dirigida a São Nicolau (c.250 - c.326), santo que é escolhido por Anselmo como um intercessor. É sobre esta oração, em particular, que gostaríamos de refletir, uma vez que, através dela, é possível compreender questóes relevantes do pensamento do Doutor Magnífico, evidenciando uma harmoniosa relação entre a oração e a especulação.

Em uma breve carta, escrita na Inglaterra, provavelmente em dezembro de $1093^{2}$, dirigida Ad Baldricum priorem et ceteros fratres Beccenses, Anselmo solicita, entre outras coisas, que lhe seja enviada uma oração que compôs quando ainda residia na abadia de Bec. Na referida oração, dirige-se a Deus, por intercessão de São Nicolau ${ }^{3}$. A Oratio ad sanctum Nicolaum é, sem dúvida, uma demonstração do típico espírito anselmiano, inspirado em Agostinho, em que o autor contrapóe à grandiosidade divina, a fraqueza da humanidade decaída.

Tal prece, à primeira vista, pode ser concebida como uma manifestação contrita de um monge piedoso. O presente estudo, no entanto, tem como escopo ir além, numa tentativa de compreensão da prece anselmiana em uma perspectiva mais ampla, situando-a no contexto maior da obra do Doutor Magnífico. Com tal objetivo, num primeiro momento, mostraremos os aspectos mais relevantes da oração, a fim de que, num momento posterior, possamos perceber os vínculos da prece com questóes relevantes do pensamento do autor.

De pronto o orante póe a claro seu estado, ou seja, a situaçáo da humanidade decaída: trata-se, efetivamente de um peccator homuncule. Consciente da sua indigência (tu multum indignes), invoca a misericórdia divina sobre sua condição miserável. Já neste momento inicial da oração, é interessante notar como Anselmo coloca a necessidade do envolvimento do pensamento (excita mentem tuam) para que seja capaz de apelar a Deus ${ }^{4}$.

${ }^{2}$ Cf a introdução de Henry Rachais na edição francesa de L'ouevre de S. Anselme de Cantorbery, v. 15 , p. 250.

${ }^{3}$ Mittite mihi orationem ad sanctum Nicolaum quam feci, et Epistolam quam contra diccta Roscelini facere inchoavi, et si quas de aliis nostris epistolis habet mommus Mauritius, quas non misit. Ep. 147, 13-15. Para todas as referências a obra de Anselmo, utilizaremos a edição de F. S. Schmitt, reproduzida e traduzida na edição francesa das obras completas do autor: L'oeuvre d'Anselme de Cantorbery: sous la Direction de Michel Corbin. Paris: Les Éditions du Cerf, 1986 ss.

${ }^{4}$ Peccator homuncule, tu multum indigens, tu qui nimis deum contristati, excita mentem tuam, intende in necessitatem tuam et invoca misericordiam tuam. Anima mea, evigila; misera mea, 
Anselmo, ressaltando a fragilidade da criatura humana, aponta, igualmente, para a grandiosidade divina. Evidenciando tais antípodas, não deixa de estabelecer um vínculo entre o criador e o que foi criado, o primeiro, altíssimo e justíssimo, o segundo, ínfimo e iníquo. Fazendo uso de uma linguagem bastante próxima da oração que abre o Proslogion e, ao mesmo tempo, afinada com Agostinho, a oração apela ao pecador, a fim de que experimente o caminho da interioridade (intrabo intra me ipsum), sem o qual não acederá à misericórdia que auspicia, mesmo sem merecer.

Tendo evidenciado a real situação do homem, decaído e, ao mesmo tempo, esperançoso, Anselmo introduz, no texto da oraçáo, a figura de Nicolau, aquele que exercerá o importante papel de intercessor. Se a atitude do pecador provoca o distanciamento de Deus, a proximidade pode ser alcançada diante da intercessão daquele que foi magnum confessorem e glorioso santo. A intercessão tem sentido, uma vez que o intercessor já é detentor da beatitude eterna. Na prece anselmiana, Nicolau parece configurar o destino eterno do homem. Transparece na oração uma certa tensão entre um funesto destino enraizado no passado e o gaudioso futuro, decorrente da vida reta.

São Nicolau parece representar o homem que manteve a retidão da vontade, alcançando a amizade definitiva com Deus. De fato, Nicolau, nome derivado do grego Nikólaos, significa povo vitorioso. O intercessor escolhido por Anselmo foi bispo de Mira e seu culto foi muito intenso entre os séculos X e XIII. Considerado homem humilde e amoroso, pode ter sido vítima da perseguição movida aos cristãos por Diocleciano. Nicolau também participou do grande concílio de Nicéia (325), sendo considerado um defensor da fé.

A menção do intercessor parece suscitar confiança ao orante pecador, a tal ponto que Anselmo parece antever uma nova perspectiva. Se até então a distância entre a grandeza divina e a fragilidade humana parecia ser desfavorável à humanidade pecadora, a partir de agora, parece que há uma inversão: permanece a distância, mas um outro par de contrários se apresenta - de um lado, a infinita misericórdia divina; de outro, a contumaz falibilidade humana. $\mathrm{O}$ rogante percebe que o pecado da humanidade é algo grave e grandioso, mas a magnitude da misericórdia divina lhe é muito superior. Portanto, apesar dos pecados, a esperança tem sentido, uma vez que um pai amoroso não dará uma pedra ao filho que lhe pede um pão.

expergiscere; scelerata mea, clama ad deum iratum tuum: si forte mitiget super te vultum suum. (Oratio ad sanctum Nicolaum, 53, 3-7). 
Imbuído de tal confiança pede a intercessão de São Nicolau, a fim de que excite seu coração e comova seu espírito, para que, experimentando as necessidades, possa usufruir dos efeitos da misericórdia. Mesmo assim, não é possível olvidar a condição do homem decaído, obrigando Anselmo a retomar o espírito e a linguagem da oração que abre o Proslogion: sua alma experimenta o torpor; além disso, o enfraquecimento da vista não permite vislumbrar um horizonte aberto e agradável. Deseja levantar os olhos a Deus, mas não é possível, pois encontra-se encurvado sob o peso do pecado. As sombras das trevas impedem o vislumbre da luz divina $a^{5}$ Tenhamos em conta que a noção de retidão é basilar na filosofia moral do pensador. Pois bem, tanto nesta prece, quanto na oraçáo inicial do Proslogion, Anselmo identifica o homem pecador como sendo aquele que está encurvado, sob o peso do pecado, ou seja, um homem que não se encontra no estado de retidão.

Anselmo compara o pecado à cegueira e à insensatez, daí dizer que estava cego, uma vez que não se protegia contra o mal que conhecia. Vê-se que Anselmo afasta-se de uma eventual perspectiva socrática, consoante a qual, o mal é feito por quem ignora o bem. Anselmo entende, do mesmo modo que o apóstolo Paulo e Agostinho, que mesmo conhecendo e querendo o bem, o homem pode fazer o mal que desejaria evitar.

Um dos pontos mais importantes da oração a São Nicolau é o momento em que Anselmo expóe, de modo breve e patente, sua compreensão do que seja o pecado. Pecar, em verdade, consiste em preferir a si mesmo em lugar do criador, o que configuraria uma grande injustiça uma vez que romperia o harmonioso ordenamento divino que estabelece a submissão ao criador. Está posta aqui, como teremos ocasiáo de ver, na singeleza de uma prece, um dos fundamentos da reflexão moral anselmiana. A condição pecadora é percebida como desumanizante, posto que vai de encontro à natureza primordial do ser humano que é de ser livre, ao passo que o pecado escraviza. Uma tal escravidão equivale a uma queda num abismo, sem possibilidade de retorno, a menos que o homem seja socorrido pela graça e misericórdia divinas ${ }^{6}$.

\footnotetext{
${ }^{5}$ Quid est quod sic cervicem meam premit? Unde sic clauditur circuitus meus? Vult, domine, vult ad deum et ad te ania mea erigere faciem suam, et ravatur pondere curvata gravatur. Cupit in vos dirigere intuitum suum, et caliginosis tenebris obscuratur. Conatur se expedire, et ferries catenis astringitur. Templat exire, et aeneo carcere clauditu. (Oratio ad Sanctum Nicolaum, 57, 77 - 58, 2).

${ }^{6}$ Quae abyssus irremeabilis est, quia nullus inde redit, nisi per gratiam retrahatur; et sine fundo, quia qui sponte peccat merito in infinitum cadit, si non per misericordiam retineatur. (Oratio ad Sanctum Nicolaum, 59, 126-128).
} 
O Doutor Magnífico, em verdade, enfatiza o caráter assombroso do pecado, de tal modo que fala de uma tríade de abismos: o pecado, o tormento pelos pecados e o julgamento divino. O primeiro configura a queda humana no pecado; o segundo é um desdobramento do anterior e parece dizer respeito às consequências da queda adâmica, uma vez que advém do pecado e é, necessariamente, ruim. O terceiro abismo mencionado, aquele do julgamento divino, faz eco ao salmo que proclama serem um grande abismo os julgamentos de Deus, uma vez que fogem da compreensáo humana .

Encaminhando-se para o final da prece, o orante pecador percebe que sua situação angustiante não o torna invisível ao olhar divino que sonda os abismos, permitindo-lhe escutar o apelo daquele que das profundezas clama ao seu criador. Anselmo expóe seu entendimento consoante o qual o resgate se dá por iniciativa divina, restando à alma pecadora reconhecer seus pecados e demonstrar arrependimento ${ }^{8}$. O pecador foi capaz de, por si só, abandonar a retidão, mas a iniciativa divina é condição imprescindível para que possa reerguer-se, dando-se conta do estado de torpor em que se encontrava em virtude de sua negligência. Anselmo parece entender que há uma ordem na criação, de modo que o plano divino em relação à humanidade náo pode deixar de realizar-se, razão pela qual Deus desce ao abismo para reerguer o homem decaído, de modo a concluir o que foi planejado? É necessário que o arrependimento humano vá ao encontro da iniciativa amorosa do criador, submetendo-se a ele ${ }^{10}$.

Reflitamos sobre o sentido da prece anselmiana, situando-a no contexto maior de sua obra. Gilbert (1990, p. 32) salienta que a exigência da compreensão, em Anselmo, tem sua origem no coração mesmo da fé, de modo que a especulação não pode ser entendida de modo dissociado da oração e da meditação. Não há dicotomia entre o monge e o intelectual; antes, o labor filosófico está perfeitamente integrado na oração, concretizando o ideal beneditino do ora et labora.

7 Iustitia tua sicut montes Dei, iudicia tua abyssus multa: homines et iumenta salvabis, Domine. [S1 36 (35),7].

${ }^{8}$ Quis enim nisi tu ad paenitendum movet animam meam, aut tu quomodo moves eam, si in abysso sua non vides eam? (Oratio ad Sanctum Nicolaum, 60, 155-157).

9 Bone deus, omnia haec fecisti in abyss, et non audis clamantem de abysso? Haec praeveniendo fugitivo tuo fecisti, et non subsequeris ad te reverti volentem, ut perficias quod incepisti? (Oratio ad Sanctum Nicolaum, 60, 161-164).

${ }^{10}$ Ego sum reus, ego ipse sum sub illo et pro illo accusator meus. (Oratio ad Sanctum Nicolaum, 61, 176-177). 
A oração que abre o Proslogion é a mais clara demonstração da íntima conexão entre filosofia e prece na obra anselmiana. A oração de que trata o presente estudo é muito próxima daquela prece, sobretudo ao mostrar a situação do homem decaído; o homem encurvado do Proslogion é o mesmo homem afundado no abismo de que fala a prece a Sáo Nicolau. Em Anselmo, a oração atua como uma espécie de pré-requisito para o esforço racional, empreendido a partir da arte dialética. Lembremos que Anselmo, ao criticar Roscelino, na Epistola De Incarnatione Verbi, declarou que uma condição absolutamente insubstituível, para todo aquele que deseja utilizar a dialética para tratar das questôes relacionadas à fé, é justamente uma firme convicção dessa mesma fé. Ora, a demonstração é realizada pelo encadeamento das razóes necessárias, mas a convicção é haurida na profundidade da oração e da meditação.

Não há, evidentemente, confusão entre oração e filosofia, pois a última apela para argumentos de natureza estritamente racionais, não necessariamente presentes na primeira. No entanto, grande parte das preces de Anselmo, inclusive a que estamos analisando, contém o que poderíamos chamar de uma certa intenção filosófica, não desconectada da perspectiva monástica de seu autor.

Cattin (1968, p. 5) afirma que a oração anselmiana é portadora das angústias, incertezas e impotências humanas. Ora, tais manifestaçôes advêm da fragilidade humana, decorrente da perda da retidão moral. No De veritate, o autor define a justiça como sendo "a retidão da verdade, observada por causa de si mesma ${ }^{11}$ ". É justamente por deixar de observar a justiça que o homem, almejando a algo que não lhe cabia desejar, acaba por perder a felicidade que possuía, além de não alcançar aquela que julgava poder encontrar. A consequência é uma vida com afliçóes, dúvidas e fraquezas.

$\mathrm{Na}$ senda paulino-agostiniana, Anselmo percebe o pecado original como algo decisivo no destino da humanidade, na medida em que significa um comprometimento importante no ordenamento divino. No Cur Deus homo, Anselmo expóe sua convicção, consoante a qual a queda adâmica consistiu em não conferir a Deus a devida honra, pois pelo próprio fato de serem criaturas, Adão e seus descendentes são ontologicamente devedores daquele que lhes fez ser. Na perspectiva do autor, uma tal dívida não é manifestação de servidão, mas uma dívida amorosa, uma vez que toda a

${ }^{11}$ Iustitia igitur est rectutudo voluntatis propter se servata. (De veritate, XII, 194, 26). 
criação está imersa numa ordem fundada na justiça e estabelecida por um Deus que é não apenas justo e amoroso, mas é a Justiça e o Amor mesmos. Na oração que analisamos, Anselmo expressa tal convicção quando diz que nada é mais justo do que a criatura se submeter a quem lhe fez ${ }^{12}$. Com o pecado, à natural dívida ontológica, acresce-se a dívida do pecado que representa, como declara Anselmo, na prece, um enganar-se a si mesmo (sed ego me traditi), uma verdadeira insanidade (inaudita insania).

A chave para a compreensão da relação do homem com Deus, tal como transparece na oração a São Nicolau, encontra-se no Monologion, a primeira obra de Anselmo, na qual trata da essência divina e outras questóes conexas; ora, entre tais questôes relacionadas a Deus, encontra-se a busca da compreensáo da origem de todas as coisas. Nos capítulos iniciais do tratado, Anselmo procura demonstrar a razoabilidade da existência de uma natureza suprema, relacionando-a, em seguida, com as outras naturezas. De fato, conforme o autor, apenas a natureza una e suprema existe por si, enquanto tudo o mais é dela derivado. Há, pois, uma diferença ontológica fundamental entre a natureza criadora, a única que é por si e de si (per se) e sua criação que deve a ela o ser (per aliud $)^{13}$.

A diferença ontológica, consoante a perspectiva cristã de Anselmo, não estabelece uma separação; antes, enseja um vínculo permanente, assentado num dever ser. Aí reside o débito ontológico, decorrente da criação. Dessa forma, como aponta Silva (2012, p. 13), "tudo o que é, porque o seu ser é devedor do próprio facto de ser, tem algo a dever". A razão disso está no fato de que criatura alguma, o homem inclusive, tem algo de si, uma vez que não tem em si mesma a razão de seu ser. No caso da criatura racional, consoante o Doutor Magnífico, este dever ser redunda numa obrigação moral, de modo que o homem deve fazer aquilo que deve, isto é, deve agir conforme a justiça. Assim procedendo não estará apenas honrando ao criador, mas atuando em conformidade com o sentido de sua existência, sentido este que implica e apela para uma justa fidelidade que culmina no encontro da felicidade.

\footnotetext{
${ }^{12}$ Quippe in pecando foedissima perversitate praeposuisti te deo tuo creator, quo nihil iniustus; in tolerantia tormentorum ordine pulchrerrimo subiceret se factura suo factori, quo nihil est iustius. (Oratio ad Sanctum Nicolaum, 59, 118-120).

${ }^{13}$ Restat igitur unam et solam aliquam naturam esse, quae sic est aliis superior, ut nullo sit inferior. Sed quod tale est, maximum et optimum est omnium quae sunt. Est igitur quaedam natura, quae est summum omnium quae sunt. Hoc autem esse non potest, nisi ipsa sit per se id quod est, et cuncta quae sunt, sint per ipsam id quod sunt. (Monologion IV, 17, 24-29).
} 
É claro que, no caso do homem, existe sempre a possibilidade de ir de encontro à ordem que o impele para a realização do sentido último da sua existência que é viver retamente, isto é, em conformidade com a justiça. $\mathrm{Na}$ oração a São Nicolau, o pecado aparece como um preferir a si mesmo em vez do criador. Anselmo evidencia um paradoxo, uma vez que, assim procedendo, o homem acaba por perder-se em densas trevas.

Em verdade, Anselmo confere um papel preponderante à vontade, entendida como o "instrumento determinante na definição do lugar que um tal ente pode ocupar no mundo, na história e na sua realização" (PALMERI, 2009, p. 56). Este lugar é evidenciado, na oração que analisamos: é a vontade humana que conduz todo homem à amizade com Deus, tal é o caso de Nicolau, ou à queda no abismo, lugar do homem cego e escravizado, o homem que abandonou a retidáo da vontade. Anselmo confere um valor singular à vontade da criatura racional, pois a amizade com o criador ou a queda no abismo passa por uma decisão fundamental da vontade. Esta ideia, presente na oração, aparece, de forma muito evidente, no diálogo De casu diaboli, quando o mestre, ante a perplexidade do discípulo, afirma que o diabo, uma criatura racional, tal como o homem, pecou, em última análise, simplesmente porque quis (non nisi quia voluit) ${ }^{14}$.

É muito interessante o papel de São Nicolau na prece em questão. Ele representa o homem reto, o homem que venceu dificuldades, mas foi capaz de manter a retidáo da vontade, a fim de agir em conformidade com a justiça. É importante destacar que, a maioria das oraçóes em que Anselmo apela aos santos, têm como destinatários personagens bíblicos. As exceçóes, como já dissemos, ficam por conta de Sáo Bento, o grande mestre do monge de Bec e São Nicolau. A oração composta por Anselmo nos possibilita compreender que Nicolau representa, de certa forma, o homem que chegou onde todos são chamados a chegar. $\mathrm{Na}$ sua figura é possível antever a concretização da esperança humana, uma vez que logrou a intimidade com Deus, tal como mostra Anselmo ao qualificá-lo como um familiar (propter alicuius tui familiaris merita).

A oração de Anselmo se movimenta em torno de três personagens: Deus, Nicolau e o homem pecador. Deus, é o criador, a quem humanidade está indissoluvelmente vinculada, Nicolau é o homem reto que alcançou a visão

${ }^{14}$ Non nisi quia voluit. Nam haec voluntas nullam aliam habuit causam qua impelleretur aliquatenus aut attraheretur sed ipsa sibi efficiens causa fuit, si dici potest, et effectum. (De casu diaboli, XXVII, 275, 31-33). 
beatífica. O homem pecador é o homem encurvado, o peccator homuncule, o homem que emerge da queda adâmica. Por mais duras que sejam as imagens relacionadas ao pecado, presentes na prece, não parece correto concluir que Anselmo assuma uma perspectiva pessimista da natureza humana. $\mathrm{Na}$ prece, assim como em sua obra especulativa, há lugar para a esperança, uma vez que o homem, mesmo antes de ser criado, é importante para Deus, a tal ponto que, após o pecado, não deixa de vir ao seu encontro com a graça salvadora. Tal dinâmica do criador para com a humanidade é bem perceptível em obras como o Cur Deus homo e o De concordia.

O Cur Deus homo é a obra em que Anselmo desenvolve aquela que ficou conhecida como sua teoria da satisfação, consoante a qual Deus criou o homem, com o intuito de que fosse feliz; com o pecado, no entanto, o próprio homem inseriu uma tal desordem na ordem criada que acarretou na perda da felicidade a que estava destinado. A única possibilidade de retomar a felicidade é a superação do pecado, mas o homem decaído não tem como fazê-lo. O homem contraiu uma dívida que não tem como pagar. Só Deus pode suprimir uma tal dívida, mas para que ela, de fato, tenha valor remissivo, é preciso que seja paga por aquele que a contraiu. Ora, o verbo encarnado, assumindo a natureza humana, resgata a humanidade do pecado. O Cur Deus homo é uma obra bastante densa e não seria possível elucidar toda sua complexidade nos limites do presente estudo. Gostaríamos, contudo, de destacar um aspecto bastante interessante da obra e que é contemplado na oração a São Nicolau: trata-se do lugar insubstituível dos homens no plano da criação.

Anselmo, ainda no primeiro livro do seu tratado cristológico enfrenta uma questáo provinda da Patrística e que encontrava apoiadores, inclusive entre alguns de seus discípulos. Entendiam alguns que o homem teria sido criado por Deus, a fim de suprir o número de anjos caídos, uma vez que não poderia existir desarmonia na cidade celeste. Anselmo coloca-se frontalmente contrário a tal tese, por entender que, ainda que nenhum anjo tivesse pecado, a criação do gênero humano fazia parte do intuito criador da divindade. Anselmo afirma que os maus anjos estavam incluídos no número desejado por Deus para integrar a cidade celeste e lá teriam permanecido, gozando da beatitude eterna, se não tivessem incorrido no erro. $\mathrm{O}$ autor não nega que a queda angélica instaura uma desordem, afetando a perfeiçáo desejada pelo criador e que tal harmonia numérica é preenchida pelo homem, uma vez que não poderia ser feita por outros anjos, criados para esse fim, uma vez que 
estes "novos" anjos conheceriam, de antemão, a situação daqueles que estavam sendo substituídos.

Até este ponto parece que Anselmo vai ao encontro da interpretação consoante a qual os homens são substitutos dos maus anjos. No entanto, no desenrolar da argumentação aponta para uma outra possibilidade, consoante a qual o número de criaturas angélicas, antes da queda, não integrava a perfeição desejada por Deus, razão pela qual, os homens que alcançam a vida eterna completam, não apenas o lugar dos anjos caídos, mas também o lugar que, desde sempre, estava a eles destinado. Assim sendo, dirá Anselmo que os homens não são meros substitutos dos anjos, uma vez que a criatura humana foi pensada como tal - pro se ipsa facta est -, de modo que, o lugar da humanidade estaria contemplado na cidade celeste, mesmo se anjo algum tivesse cometido pecado.

Tal compreensão bem mostra a singularidade e a importância do homem no plano celeste. É por saber-se querido por Deus que o homem da prece anselmiana, embora pecador, consegue, mesmo do fundo do abismo, esboçar um sentimento de esperança, uma vez que confia que aquele que fez todas as coisas, não condenará sua criatura, ainda que tenha cometido pecado por iniciativa própria. A criatura, no entanto, acusa seu pecado, confiando que "se és um juiz para julgar o culpado, és também o Mestre para proteger teu servo e és o criador para conservar tua obra e és Deus para salvar aquele que crê e recebeu o batismo" 15 .

É perceptível, na oração a São Nicolau, a presença de uma certa ambiguidade: de um lado, revela-se a natureza humana decaída, imersa em grande tristeza; de outro lado, transparece um sentimento de esperança, fundada, náo tanto na capacidade humana de arrepender-se, quanto na confiança de que a graça divina possa vir ao encontro daquele que se encontra inconsolável no fundo do abismo. A tristeza é uma realidade, no entanto, ela não compromete irreversivelmente a natureza humana, feita para a felicidade, uma vez que a esperança, não por acaso, uma virtude teologal, aponta para a possibilidade do resgate. Náo esqueçamos que, para o Doutor Magnífico, o ser humano tem sua razáo de ser ancorada na vontade de um Deus que é bom e que tudo faz em consonância com tal bondade. Assim sendo, o homem foi feito bom e para o bem. Anselmo, uma vez mais, compartilha da

\footnotetext{
${ }^{15}$ Solus suffeci ad peccandum, solus sufficiam ad accusandum. Denique si iudex est ad judicandum reum suum: est si dominus ad tuendum servum suum, est creator ad servandum opus suum, est deus ad salvandum credentem et baptizatum suum. (Oratio ad Sanctum Nicolaum, 61, 178-181).
} 
mesma convicção de Agostinho, razão pela qual ambos apelarão para o papel imprescindível da graça divina, a fim de que o homem, uma vez decaído, possa ir ao encontro do escopo originário de sua criação que é a vida feliz, na presença de Deus. No caso de Agostinho, a defesa da graça é ensejada pela polêmica com Pelágio (c. 354 - c. 420). De fato, Pelágio rebelava-se contra o que entendia ser uma frouxidão da vida cristá. Ele acreditava que o ser humano seria capaz de cumprir os mandamentos divinos; se assim não fosse, por que razão teria Deus conferido à humanidade seus preceitos? Tendo sido criado com liberdade e, orientado pelas Sagradas Escrituras, o homem, consoante Pelágio, teria todas as condiçóes de escolher o que é correto e evitar o que é mau, aos olhos do criador. A razáo maior da polêmica agostiniana com os seguidores de Pelágio reside no fato de que, para eles, a queda adâmica náo teria afetado a humanidade, como um todo. Não seria o pecado do gênero humano, mas de um indivíduo. Pelágio náo deixava de destacar a singularidade desse ato, mas sua importância residia no fato de que se constituiu num detestável exemplo para os seus descendentes. O primeiro homem foi um mau exemplo. No entanto, de maneira absolutamente diversa, a humanidade encontrou em Jesus Cristo, o homem que consegue viver conforme o plano divino. Ao colocar Adão como tão somente um mau exemplo, Pelágio busca concentrar no indivíduo a responsabilidade pelos pecados cometidos. É o indivíduo que peca e é o indivíduo que, pelo seu esforço, consegue a salvação.

Agostinho, por seu turno, entende a queda adâmica como um pecado de origem, transmitido a todos os homens. A saída da humanidade do estado pré-lapsariano inaugura uma tal desordem que a criatura humana, por si mesma, não tem como remediar. Destarte apenas a encarnação do Verbo e a graça divina permitem o restabelecimento da ordem que pode conduzir o gênero humano à felicidade, a qual esteve, desde sempre, destinado.

O entendimento anselmiano sobre a natureza humana, bem como a necessidade da graça vai ao encontro de Agostinho, mas o tom é outro, até mesmo pelo fato de sua reflexão não se situar num contexto tão complexo de embate argumentativo, tal como o Bispo de Hipona. Em Anselmo, poderíamos dizer que a graça divina não se desvincula da retidão. A retidão, de fato, é graça e, por tal razão, não abandona a vontade humana; ou melhor, só abandona a vontade humana se tal vontade quer algo que vá de encontro à retidão, pois a vontade de conservar a retidão passa pelo livre arbítrio. No terceiro livro do De concordia está explicitado, discursivamente, a mesma ideia que transparece na prece que analisamos: a graça, tal como o livre-arbítrio são necessários para 
que o homem decaído, possa gozar da familiaridade divina. No entanto, o homem que pôde cair, por si mesmo, só poderá reerguer-se com o auxílio da graça, fazendo com que sua esperança não seja em vão.

Ao analisarmos esta prece de Anselmo, podemos perceber algo análogo ao que encontramos na oração de Agostinho, no início dos Solilóquios. Muitos temas importantes da obra do hiponense estão refletidos naquela prece, tais como a criação e a ordem do mundo, o problema do mal, o livre arbítrio, a interioridade, a participação na Verdade, a felicidade, a necessidade da graça etc. Não é diferente o que encontramos na Oratio ad sanctum Nicolaum, uma vez que, como tivemos ocasião de apontar, questóes relevantes da obra discursiva de Anselmo estão bem refletidas em sua prece.

Em seu primeiro tratado, o Monologion, Anselmo apresenta um método de investigação que, via de regra, vai acompanhá-lo ao longo de sua produção filosófica: argumentar sola ratione, a fim de que todas as demonstraçóes estivessem fundamentadas no encadeamento argumentativo, propriamente dito e não na força da autoridade. Tal postura qualificaria a reflexão anselmiana como sendo de índole racionalista. $\mathrm{O}$ presente estudo aponta para uma outra direção. Há, por certo, uma distinção, mas Anselmo não sobrepóe a razão à fé. Quisemos mostrar a harmoniosa integração entre a fides e a ratio no pensamento anselmiano. A especulação e a oraçáo não divergem, mas se complementam, a tal ponto de Barth (1985, p. 19) dizer que "o conhecimento está inelutavelmente associado ao amor de Deus contido na fé".

A prece, na verdade, atua como uma espécie de preparação para o trabalho racional, propriamente dito. $\mathrm{O}$ trabalho da razáo, ainda que realizado na fidelidade ao rigor dialético, está todo ele assentado em convicçóes de fé que brotam da meditação e da oração monásticas. Não se trata, contudo, de uma fé acomodada, mas de uma fé que busca a compreensão, uma fé que vai ao encontro do conhecimento. Por isso a obra de Anselmo, como um todo, é a mais legítima manifestação do fides quaerens intellectum. 
VASCONCELLOS, M. The harmony of reason and prayer in the thought of Anselm of Aosta. Trans/Form/Ação, Marília, v. 42, p. 217-230, 2019. Edição Especial.

\begin{abstract}
Aвstract: This article analyzes one of the prayers of Anselm of Canterbury (1033-1109), namely, the Prayer to Saint Nicholas. We aim to show how it is possible to find relevant aspects of the author's philosophical-theological output reflected in the prayer, mainly in relation to the situation of man, marked by sin, once rectitude and will are abandoned. In the prayer, as well as in his speculative work, Anselm examines the situation of sinful man in the face of divine grace and mercy. We highlight the existence in Anselm's work of a harmonious relationship between prayer and speculation, in conformity with the Benedictine ideal of ora et labora.
\end{abstract}

KeYwords: Anselm. Prayer. Man. Sin.

\title{
REFERÊNCIAS
}

ANSELME DE CANTORBERY. L'oeuvre de S. Anselme de Cantorbery: sous la Direction de Michel Corbin. Paris: Cerf, 1986ss.

BARTH, K. Fides quaerens intellectum: la preuve de l'existence de Dieu. Géneve: Labor et Fides, 1985.

CATTIN, I. La preuve de Dieu. Paris: Vrin, 1968.

GILBERT, P. Le Proslogion de S. Anselme. Roma: Editrice PUG, 1990.

PALMERI, P. Voluntas e rectitudo nella riflexxione etico-filosofica di Anselmo d'Aosta. Palermo: Officina di Studi Medievali, 2009.

ROCHAIS, H. Avant propos. In: L'oeuvre de S. Anselme de Cantorbery: sous la direction de Michel Corbin. Paris: Editions du Cerf, 1988. p. 247-250. V. 5.

SILVA, P. Introdução. In: Anselmo de Cantuária: diálogos filosóficos. Porto: Ediçōes Afrontamento, 2012. p. 7-48.

Recebido: 30/12/2019

Aceito: 30/12/2019 
VASCONCELLOS, M. 